\title{
RESEARCH
}

Open Access

\section{Predictors of instantaneous relief from spinal manipulation for non-specific low back pain: a delphi study}

Stanley Innes ${ }^{1 *} \mathbb{D}$, Amber Beynon ${ }^{1}$, Christopher Hodgetts ${ }^{1}$, Rachel Manassah², Denyse Lim² and Bruce F. Walker ${ }^{1}$

\begin{abstract}
Background: There is some evidence and anecdotal reports that high-velocity low-amplitude (HVLA) spinal manipulation therapy (SMT) for non-specific low back pain (NSLBP) may immediately reduce pain in some patients. The mechanism for such a change remains unclear and the evidence is conflicting. The aim of this study was to seek consensus among a sample of expert manual therapists as to the possible clinical predictors that could help identify patients who are most likely to receive instant relief from NSLBP with SMT intervention.

Methods: Thirty-seven expert chiropractors and manipulative physiotherapists from around the world were invited to participate in a three round online Delphi questionnaire during the second half of 2018. Participants were provided with a list of 55 potential signs and symptoms as well as offering them the option of suggesting other factors in the first round. The variables were rated using a 4-point Likert likelihood scale and a threshold of 75\% agreement was required for any item to progress to the next round.

Results: Of these 37 experts, 19 agreed to participate. Agreement as to the proportion of patients who receive instantaneous relief was minimal (range 10-80\%). A total of 62 items were ranked over the 3 rounds, with 18 of these retained following the third round. The highest rated of the 18 was 'A history including a good response to previous spinal manipulation'.

Discussion/conclusion: Five categories; patient factors, practitioner factors, signs and symptoms of NSLBP presentation, an instrument of measurement (FABQ), and the presence of cavitation following SMT best describe the overall characteristics of the factors. The 18 factors identified in this study can potentially be used to create an instrument of measurement for further study to predict those patients with NSLBP who will receive instantaneous relief post-SMT.
\end{abstract}

Keywords: Spinal manipulation, Delphi, Instantaneous response

\footnotetext{
*Correspondence: S.Innes@murdoch.edu.au

${ }^{1}$ Psychology, Exercise Science, Counselling and Chiropractic, Murdoch University, Murdoch, Australia

Full list of author information is available at the end of the article
}

C C The Author(s). 2020 Open Access This article is licensed under a Creative Commons Attribution 4.0 International License, which permits use, sharing, adaptation, distribution and reproduction in any medium or format, as long as you give appropriate credit to the original author(s) and the source, provide a link to the Creative Commons licence, and indicate if changes were made. The images or other third party material in this article are included in the article's Creative Commons. licence, unless indicated otherwise in a credit line to the material. If material is not included in the article's Creative Commons licence and your intended use is not permitted by statutory regulation or exceeds the permitted use, you will need to obtain permission directly from the copyright holder. To view a copy of this licence, visit http://creativecommons.org/licenses/by/4.0/ The Creative Commons Public Domain Dedication waiver (http://creativecommons.org/publicdomain/zero/1.0/) applies to the data made available in this article, unless otherwise stated in a credit line to the data. 


\section{Background}

Physiotherapists, osteopaths and chiropractors are among health professions with a special interest in the diagnosis, management and prevention of musculoskeletal disorders, especially back pain $[1,2]$. Patients suffering from musculoskeletal conditions are often treated using manual therapy by these practitioners. A common intervention used by these practitioners are spinal manipulation techniques (SMT) [2-4]. The current literature and anecdotal evidence in clinical practice suggests that SMT is utilized with the aim of improving joint ranges of motion, releasing muscular tension in order to improve joint function and decrease or relieve musculoskeletal pain $[5,6]$.

Some studies suggest that the mechanical force induced by an effective high-velocity low-amplitude (HVLA) technique to a specific spinal segment can induce immediate pain relief $[7,8]$, others disagree [9]. The literature posits a number of theories to explain this possible outcome, including but not limited to, neurophysiological and biomechanical effects [10], enhanced facet joint motion, intraarticular or myofascial adhesions, and soft tissue inclusions entrapped between facet joints [8, 9, 11-13]. Some suggest that this may not be exclusive to SMT $[14,15]$.

There has been a call to action by prominent researchers for a change in the way low back pain (LBP), one of the most commonly encountered musculoskeletal conditions [16], is managed [17], in an effort to reduce the huge financial impact placed on economies [18]. One recommendation was for the reduction of care that yields marginal benefits at a disproportionately high cost (low value care) [17]. In support of this concern is recent research that shows that chiropractic students are not good at predicting when SMT will not make a difference to patient outcomes $[19,20]$. Given that any intervention should be targeted to those who are likely to gain the most benefit, it logically follows that knowing the clinical predictors is important when selecting patients for HVLA SMT [21]. It is hypothesized and anecdotally reported, that there is a subgroup of the population who respond to spinal manipulation with instantaneous relief, and that these patients can be identified prior to treatment [7]. It is known that the most favourable prognostic group undergoing chiropractic care (common users of HVLA SMT) at the fourth consultation are those who respond strongly after the first consultation [22, 23]. However, understanding and identifying who is included in this population is poorly reported in the literature and not well researched [7]. Chiropractors have been shown to be poor predictors of those most likely to respond positively to care [24]. Thus the ability to identify a group of people who respond strongly and immediately to SMT could contribute to the reduction of low value care and improve the quality of patient care.
The aim of this study was to seek consensus among a sample of expert manual therapists as to the possible clinical predictors that could help identify patients who are most likely to receive instant relief from NSLBP with SMT intervention.

\section{Methods}

\section{Rationale for Delphi technique}

To address our research question a Delphi technique was chosen because the technique is considered to have a qualitative dimension that is appropriate when quantitative methods are unlikely to yield results that can be relatively easily gathered or be readily implemented into practice [25]. The Delphi technique employed for this study used a literature review to create the initial item list and a focus group to review and pilot test the survey.

\section{Development of the questionnaire}

The questionnaire was developed in two stages: 1) item generation 2) item selection.

\section{Stage 1. Item generation}

The items were generated via a review and analysis of the literature looking for signs and symptoms possibly linked to immediate relief from NSLBP following SMT. The literature search strategy used the MeSH and non$\mathrm{MeSH}$ keywords: spinal manipulation, instant relief, immediate relief/response, non-specific low back pain, predictors of instant relief, predictors of immediate relief, predictors, indicators, and prevalence. Databases used were Google Scholar, PubMed, and Cochrane Library.

A focus group comprised of three manual therapy academics (BFW, $\mathrm{AB}, \mathrm{CH}$ ) and seven final year chiropractic students reviewed the item list for interpretability and created some additional items based on biological and clinical plausibility. This resulted in a list of 55 items (Table 1).

\section{Stage 2. Item selection}

A three round Delphi survey process [26, 27] was conducted by email correspondence to select and refine the collated items (see Fig. 1). The purpose of the survey was to see if any aspect that would lead to an item was overlooked, reach a consensus among the expert manual therapists regarding the signs and symptoms most likely to identify individuals who would respond immediately to HVLA SMT, and the likely percentage composition of daily practice this was thought to constitute.

\section{Participants: sample size, expert criteria and recruitment}

Participants were selected on the basis of their relationship with the study phenomenon and following a criteria of suitability [28]. The criteria were 1) manual therapists registered as either chiropractors and/or manipulative physiotherapists with knowledge and interest in the subject as 
Table 1 The initial 55 item list of patient characteristics to predict patients likely to obtain immediate relief from NSLBP following SMT

\begin{tabular}{|c|c|}
\hline 1. Duration of symptoms $<16$ days & 2. Pain associated with coughing or sneezing \\
\hline $\begin{array}{l}\text { 3. Fear Avoidance Beliefs Questionnaire work scale score less } \\
\text { than } 19 \text { out of a high of } 42 \text { (low fear category) }\end{array}$ & $\begin{array}{l}\text { 4. A history including a good response to previous } \\
\text { spinal manipulation }\end{array}$ \\
\hline 5. At least one hip with $>35$ degrees of internal rotation & 6. Patient has an acute condition ( $<14$ days) \\
\hline 7. Hypomobility in the lumbar spine & 8. Patient has a subacute condition (> 3 months) \\
\hline 9. No symptoms distal to the knee & 10. Patient has a chronic condition (> 3 months) \\
\hline 11. Morning stiffness $\leq 30$ mins & 12. Age $10-30$ \\
\hline 13. Morning stiffness $>30$ mins & 14. Age $31-49$ \\
\hline 15. Pain improves with exercise, but not rest & 16. Age $50+$ \\
\hline 17. Pain on waking, duration $>30$ mins & 18. Female \\
\hline 19. Pain on waking, duration $\leq 30$ mins & 20. Male \\
\hline 21. Pain wakes the patient at night & 22. Patient $\mathrm{BMI}<35$ \\
\hline 23. Experiences stiffness after rest (gel phenomenon) & 24. Patient $\mathrm{BMI} \geq 35$ \\
\hline 25. Pain present at all times & 26. Professional opinion of health status - fair/poor \\
\hline 27. Pain intermittently during the day & 28. Professional opinion of health status - good \\
\hline 29. Pain develops later in the day & 30. Professional opinion of health status - excellent/ very good \\
\hline 31. Pain associated with standing for a while & 32. Patient experiencing depression \\
\hline 33. Pain associated with lifting & 34. Patient experiences anxiety \\
\hline 35. Pain associated with bending forward a little & 36. Patient is stressed \\
\hline 37. Pain associated with bending forward as far as they can & 38. Good patient - practitioner relationship \\
\hline 39. Pain associated with arching backwards & 40. Patient has a comprehensive understanding of condition \\
\hline 41. Pain associated with doing or attempting to do a sit up & 42. Previous episode of NSLBP in patient history \\
\hline 43. Pain associated with driving long distances & 44. Pain affecting activities of daily living \\
\hline 45. Pain associated with getting out of chair & 46. Patient responds well to anti-inflammatory medicine \\
\hline 47. Pain associated with repetitive bending & 48. Decreased active range of motion \\
\hline 49. Pain associated with running & 50. Decreased passive range of motion \\
\hline 51. No symptoms in the lower extremities & 52. Pain severity $\leq 5 / 10$ \\
\hline 53. Pain severity rated $>5 / 10$ & 54. Recurrent attack of pain \\
\hline 55. First episode of pain & \\
\hline
\end{tabular}

demonstrated by using HVLA SMT as a primary intervention for NSLBP; 2) had been using HVLA SMT for at least 5 years; 3 ) had experienced a patient response of immediate pain relief from HVLA SMT. Meeting these criteria was deemed to indicate that the practitioner participants had obtained a level of proficiency from clinical experience to have formed an opinion about NSLBP patients likely to benefit from SMT [26].

On the basis of past research, at least 7 to 10 experts from each of the chiropractic and physiotherapy disciplines needed to be recruited to obtain consensus $[25,26]$.

Recruitment began by emailing "experts" known to the authors for their clinical experience, after which a 'snowball' recruitment method was employed. The email contained a written invitation with an information letter explaining the methods and expectations. The manual therapists were also advised that they were participating in a peer group task endeavouring to work towards an end goal of consensus [27].

\section{Procedure for Delphi rounds and definition of consensus} An online survey (Survey Monkey [29]) was created to allow for easy access for all participants and efficient collection of data and could be completed in the consenting practitioners' own time within 1 week. The methodology and timeline is outlined in Fig. 1.

\section{Round 1}

During the first round of the survey participants were blinded to their colleagues' opinions and answered the survey anonymously. They were asked to rate the 55 items on a prediction scale that was structured as a modified 4-point Likert scale, which ranged from "Not predictive" to "Most predictive" (Additional file 1). A 


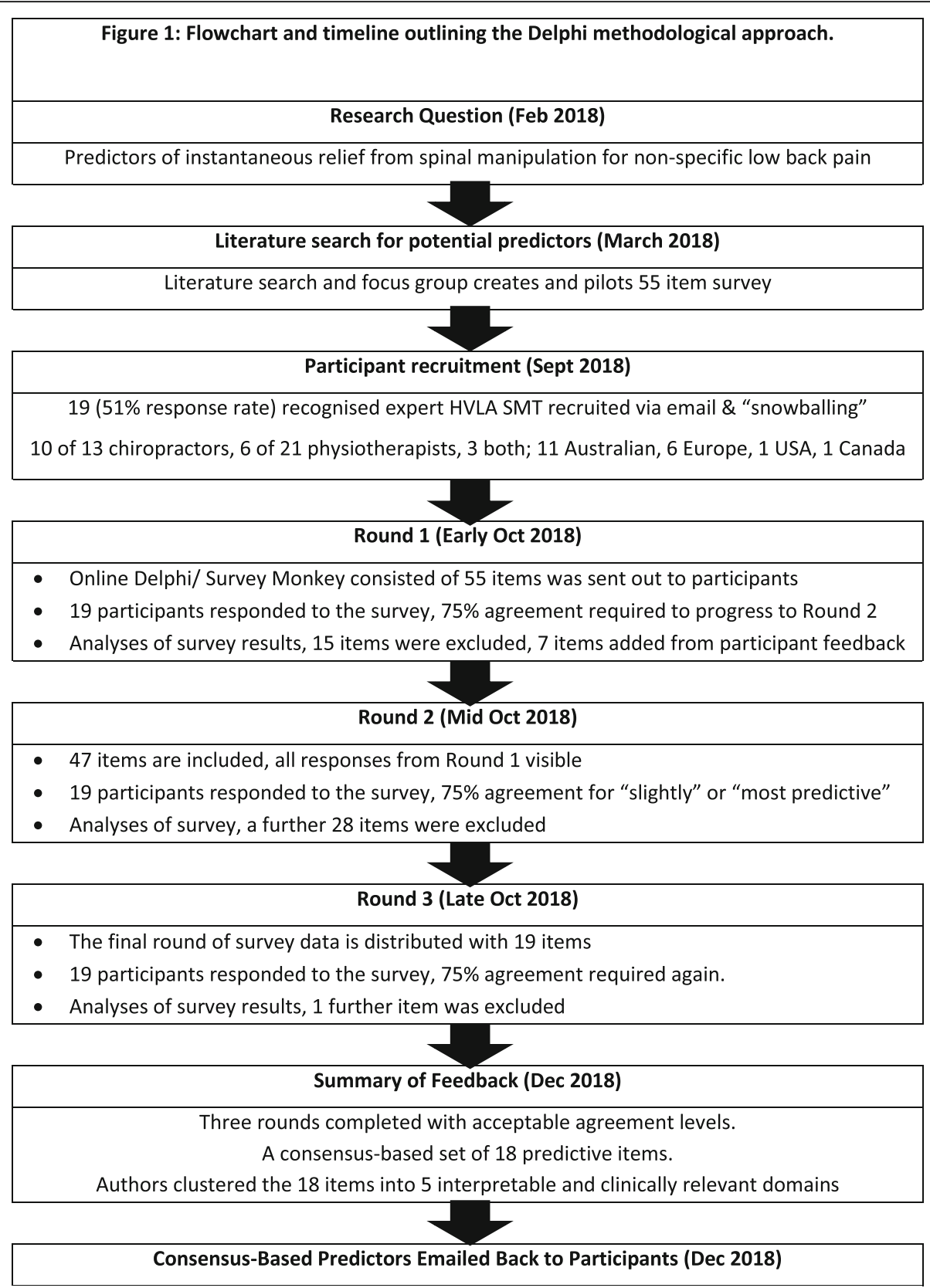

Fig. 1 Flowchart and timeline outlining the Delphi methodological approach

neutral response option was not provided as it would have given limited information to the research [27]. They were also invited to provide any additional signs or symptoms that may be applicable and had been overlooked. Responses were collated and reviewed by three of the authors $(\mathrm{AB}, \mathrm{DL}, \mathrm{RM})$. Items where $75 \%$ of participants regarded the item to be 'negatively predictive' (not predictive or slightly un-predictive) were excluded from Round 2. Items that independently emerged from the open responses provided by practitioners were added to Round 2 and distributed again to the expert practitioners (Table 2).

\section{Round 2}

After the second round, the item list was once again revised by three members of the team (AB, DL, RM). This time items were retained if $75 \%$ of participants agreed they were positively predictive (most predictive or slightly predictive).

\section{Round 3}

For the Round 3 distribution, the predictor variables with $50 \%$ agreement or more as being 'most predictive' from Round 2 were ordered by desirability and placed at the top of the survey [25]. This revealed to the participant the 
Table 2 Shows the percentage of participants who responded "positively predictive" to the list of patient characteristics that may help predict instantaneous relief from NSLBP following SMT

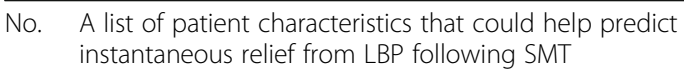

2. Morning stiffness $\leqslant 30$ mins

3. A history including a good response to previous spinal manipulation

4. Good patient-practitioner relationship

5. No symptoms distal to the knee

6. Patient has an acute condition (< 14 days)

7. Professional opinion of health status - excellent/ very good

8. Fear Avoidance Beliefs Questionnaire work scale score less than 19 out of a high of 42 (low fear category)

9. Professional opinion of health status - good

10 Patient has a comprehensive understanding of condition

11. Hypomobility in the lumbar spine

12. Pain improves with exercise, but not rest

13. Patient has a sub-acute condition (15 days to 3 months)

14. Age $31-49$

15. Decreased active range of motion

16. Pain intermittently during the day

17. Previous episode of non-specific LBP in patient history

18. Decreased passive range of motion

19. No symptoms in the lower extremities

20. Pain severity rated $\leqslant 5 / 10$

21. Experiences stiffness after rest (gel phenomenon)

22. Pain associated with getting out of a chair

23. Pain affecting activities of daily living

24. Pain associated with bending forward a little

25. Pain associated with arching backwards

26. Age $10-30$

27. Recurrent attack of pain

28. First episode of pain

29. Pain associated with standing for a while

30. Pain associated with lifting

31. Pain associated with bending forward as far as they can

32. Age $50+$

33. Pain on waking, duration $\leqslant 30$ mins

34. At least one hip with $>35$ degrees of internal rotation

35. Pain on waking, duration $>30$ mins

36. Pain associated with repetitive bending

37. Pain associated with running

38. Patient $\mathrm{BMI}<35$

39. Patient responds well to anti-inflammatory medicine

40. Pain severity rated $>5 / 10$

41. Pain associated with doing or attempting to do a sit up
Percentage of participants who responded that the item is positively predictive (\%)

Round 1 Round 2 Round 3

$94 \quad 69=$

$94 \quad 100 \quad 100$

94

88

100

94

88

88

81

81

75

75

75

75

75

69

69

69

63

63 
Table 2 Shows the percentage of participants who responded "positively predictive" to the list of patient characteristics that may help predict instantaneous relief from NSLBP following SMT (Continued)

\begin{tabular}{|c|c|c|c|c|}
\hline \multirow[t]{2}{*}{ No. } & \multirow[t]{2}{*}{$\begin{array}{l}\text { A list of patient characteristics that could help predict } \\
\text { instantaneous relief from LBP following SMT }\end{array}$} & \multicolumn{3}{|c|}{$\begin{array}{l}\text { Percentage of participants who } \\
\text { responded that the item is } \\
\text { positively predictive (\%) }\end{array}$} \\
\hline & & Round 1 & Round 2 & Round 3 \\
\hline 42. & Pain associated with driving long distances & 25 & - & - \\
\hline 43. & Female & 25 & - & - \\
\hline 44. & Male & 25 & - & - \\
\hline 45. & Pain present at all times & 19 & - & - \\
\hline 46. & Pain develops later in the day & 19 & - & - \\
\hline 47. & Pain associated with coughing or sneezing & 19 & - & - \\
\hline 48. & Morning stiffness $>30$ mins & 15 & - & - \\
\hline 49. & Pain wakes the patient at night & 13 & - & - \\
\hline 50. & Patient has a chronic condition (> 3 months) & 13 & - & - \\
\hline 51. & Patient $\mathrm{BMI} \geq 35$ & 13 & - & - \\
\hline 52. & Professional opinion of health status - fair/poor & 7 & - & - \\
\hline 53. & Patient experiencing depression & 7 & - & - \\
\hline 54. & Patient experiences anxiety & 7 & - & - \\
\hline 55. & Patient is stressed & 7 & - & - \\
\hline 56. & Pain onset related to a specific physical activity & $\mathrm{n} / \mathrm{a}$ & 56 & - \\
\hline 57. & The production of a clicking sound (cavitation) at the moment of thrust & $\mathrm{n} / \mathrm{a}$ & 81 & 76 \\
\hline 58. & Taking a comprehensive history & $\mathrm{n} / \mathrm{a}$ & 75 & 65 \\
\hline 59. & Practitioner understanding of patient expectations and goals & $\mathrm{n} / \mathrm{a}$ & 88 & 94 \\
\hline 60. & Close reproduction of symptoms on spinal springing and/ or end range loading & $\mathrm{n} / \mathrm{a}$ & 81 & 76 \\
\hline 61. & Patient susceptible to placebo effect & $\mathrm{n} / \mathrm{a}$ & 88 & 88 \\
\hline 62. & Patient has trust and confidence in the practitioner & $\mathrm{n} / \mathrm{a}$ & 81 & 100 \\
\hline
\end{tabular}

Key: $\mathbf{n} / \mathbf{a}$ : scores for these items are not available in Round 1 as they were added in Round 2 based on suggestions provided by participants in Round 1. -: items that did not get scored as they had been removed from the survey.

popular and less popular options, giving them the opportunity to re-evaluate, re-think and either retain or change their original answer [26].

After three rounds, the four-point Likert scale of "not predictive", "slightly un-predictive", "slightly predictive" and "most predictive" was assigned a score of $-2,-1,1$ and 2 respectively. This allowed for the final list of predictors that achieved a $75 \%$ level of agreement to be ranked based on their predictive scores by mean score and sum. A table was then generated allowing for notional weighting of the variables in order of their predictive score. This methodology ensured all possible options had been considered, estimated the consequential power of any particular option, and examined and estimated the acceptability of any particular option [28].

\section{Ethics}

Sex, occupation and number of years of clinical experience were asked at the end of the survey. Participants remained anonymous and were not required to give any identifying information. Each participant received an online information letter and consent form (Additional file 1). The study was granted ethics approval by the Murdoch University Human Research Ethics Committee (2018/163).

\section{Results \\ Participants}

Thirty-seven experts (13 chiropractors, 21 physiotherapists, and 3 who were qualified as both a chiropractor and physiotherapist) were approached to participate. Of these 19 agreed to participate (51\% response rate) comprising 10 chiropractors, 6 physiotherapists, and 3 who were qualified as both. The experts were from Australia $(n=11)$, Canada $(n=1)$, Denmark $(n=1)$, Germany $(n=$ $1)$, Sweden $(n=1)$, United Kingdom $(n=3)$, and United States of America $(n=1)$.

\section{Round 1}

The response rate for Round 1 was 18/19, Round 2 was $17 / 19$ and Round 3 was 17/19. In Round 1 of the 18 participants who responded two were excluded as they responded positively to the exclusion question of not 
having observed an immediate response to SMT in their practice. This was despite them answering positively to the question in the formative information stage. Consequently 16 responses were analysed. Fifteen possible predictor items were excluded after Round 1 because they did not achieve the threshold value of at least $75 \%$ agreement (Table 2). Seven additional possible signs or symptoms were suggested from Round 1 responses and were added into the survey for Round 2 (Table 2). These items included aspects of a therapeutic alliance namely, the patient having trust and confidence in the practitioner, the practitioner understanding the patient expectations and goals and the presence of a comprehensive history. Also included was the presence of a cavitation during treatment, reproduction of symptoms at the end of ranges of motion or on spinal springing and the patient being susceptible to placebo.

The mean estimated score of the percentage of patients who participants believed experienced instantaneous relief from SMT approached 40\% (SD 27.5\%) and ranged from a low of $10 \%$ to a high of $80 \%$. Round 2 responses produced highly similar results for this question and consequently was not included in Round 3.

\section{Round 2}

In Round 2, 17 participants responded, and one practitioner was excluded as they also had not observed an immediate beneficial response to SMT in practice. The responses were analysed and a further 28 variables were excluded (Table 2) on the same basis that they did not achieve at least $75 \%$ agreement of being "slightly" or "most predictive". Consequently 19 variables were included for Round 3.

\section{Round 3}

In Round 3, there were 17 participants, none were excluded. The highest predictor of instantaneous relief from NSLBP following SMT was "a history including a good response to previous spinal manipulation" (Table 2 ). This was the only predictor to attain a score of $75 \%$ agreement of being "most predictive". There was only one item that did not meet the $75 \%$ agreement criterion of being "slightly" or "most predictive", which was "taking a comprehensive history" and was therefore removed resulting in a final list of 18 items. The predictive scores for each item was then calculated (mean score, SD, sum and ranges) and are seen in Table 3. Many of the items appeared to cluster together and represented distinct

Table 3 Final 18 predictor items placed in 5 Domains ranked by mean score and sum

\begin{tabular}{|c|c|c|c|c|c|c|}
\hline Predictors & Mean & Std. Deviation & Sum & Range & Minimum & Maximum \\
\hline \multicolumn{7}{|l|}{ Patient factors } \\
\hline Patient history of a good response to previous SMT & 1.88 & 0.33 & 32 & 1 & 1 & 2 \\
\hline Patient has trust and high confidence in the practitioner & 1.35 & 0.49 & 23 & 1 & 1 & 2 \\
\hline Patient susceptible to placebo effect & 0.94 & 1.03 & 16 & 4 & -2 & 2 \\
\hline Patient has a comprehensive understanding of condition & 0.76 & 0.90 & 13 & 3 & -1 & 2 \\
\hline \multicolumn{7}{|l|}{ Practitioner factors } \\
\hline Good patient-practitioner relationship & 1.35 & 0.49 & 23 & 1 & 1 & 2 \\
\hline Professional opinion of health status - excellent/ very good & 1.18 & 0.73 & 20 & 3 & -1 & 2 \\
\hline Practitioner understanding of patient expectations and goals & 1.06 & 0.66 & 18 & 3 & -1 & 2 \\
\hline Professional opinion of health status - good & 0.88 & 0.99 & 15 & 3 & -1 & 2 \\
\hline \multicolumn{7}{|l|}{ Signs and symptoms of NSLBP presentation } \\
\hline Duration of symptoms $<16$ Days & 1.06 & 1.09 & 18 & 4 & -2 & 2 \\
\hline Pain improves with exercise, but not rest & 1.06 & 1.09 & 18 & 4 & -2 & 2 \\
\hline No symptoms in the lower extremities & 1.00 & 0.87 & 17 & 4 & -2 & 2 \\
\hline Patient has an acute condition ( $<14$ days) & 0.94 & 1.20 & 16 & 4 & -2 & 2 \\
\hline No symptoms distal to the knee & 0.94 & 1.20 & 16 & 4 & -2 & 2 \\
\hline Decreased active range of motion & 0.76 & 1.09 & 13 & 4 & -2 & 2 \\
\hline Decreased passive range of motion & 0.76 & 1.09 & 13 & 4 & -2 & 2 \\
\hline Close reproduction of symptoms on spinal springing and/or end range loading & 0.65 & 1.32 & 11 & 4 & -2 & 2 \\
\hline \multicolumn{7}{|l|}{ An instrument of measurement (FABQ) } \\
\hline Fear Avoidance Beliefs Questionnaire work scale score less than 19 out of a high of 42 & 0.82 & 0.95 & 14 & 4 & -2 & 2 \\
\hline \multicolumn{7}{|l|}{ The presence of a cavitation following SMT } \\
\hline The production of a the clicking sound (cavitation) at the moment of thrust & 0.71 & 1.21 & 12 & 4 & -2 & 2 \\
\hline
\end{tabular}


domains that were clinically relevant and interpretable. After a post hoc discussion among the authors, the items were placed into five domains: Patient factors; Practitioner factors; Patient signs and symptoms; Instrument of measurement; Presence of cavitation with SMT.

\section{Interpretation of non-consensus}

The items that were not included in Round 1 and 2 (did not reach consensus), were indicative of a patient with a significant, chronic and disabling LBP. The items included persistent and highly rated pain, the presence of psychosocial factors (depression / anxiety / stress), and pain on coughing sitting and at night. Items that did not fit this profile were gender, and any specific age range.

The non-consensus items not included in Round 3 were again indicative of a more chronic LBP patient presentation. Items such as subacute, pain with motion (sit, stand, run, walk, flex, extend), obesity, and morning gel phenomena were rated poorly as likely predictors of instant response. However, some non-consensus items appeared not to match the profile of a chronic LBP patient and included low ratings of pain severity, a poor response to NSAIDs, and lumbar spine hypomobility.

\section{Discussion}

This is, to our knowledge, the first study to seek the opinion of experts' in HVLA SMT as to factors that may predict a person who will have an immediate positive response. We presented a total of 62 items to 17 experts, which was ultimately reduced to 18 items using a modified Delphi methodology. These items were able to be allocated into 5 clinically relevant domains.

It appears logical that the most highly rated predictive factor for a patient to experience an instantaneous positive response to HVLA SMT for NSLBP was "a history that included a good response to previous spinal manipulation". In support of this opinion is previous research that showed an immediate response on the first consultation was highly predictive of the outcome at the fourth consultation [22]. Also, a good response to prior SMT identified patients most likely to respond to maintenance care for NSLBP [30]. Finally, if a patient has had a previous positive experience then their expectations would more likely be for a similar result and such expectations are known to be predictive of treatment outcomes [31, 32].

The items, "A patient with high trust and confidence in the practitioner", "a good patient-practitioner relationship", "patient has comprehensive understanding of a condition" and "practitioner understanding of patient expectations" were all highly agreed upon predictors and reflect known aspects of a therapeutic alliance [33]. A high-quality therapeutic alliance has been shown to be a significant contributor to the outcomes of patients with NSLBP undergoing manual therapy [34-36]. Some have suggested that the therapeutic alliance plays a mediating role in patient outcomes [34]. If so, then this Delphi survey constructed item list may be identifying aspects of the practitioner-patient interaction that maximizes the impact of the therapeutic alliance when a manual therapist is using HVLA SMT as an intervention, and as such warrant's further investigation.

There were two items in the final list that were in accord with factors known to impact negatively on outcomes of patients experiencing LBP. These were the presence of co-morbidities [37, 38] ("opinion of health status") and psychosocial factors [39] ("FABQ Work scale"). If the practitioner identifies that there are no "Yellow flags" then time consuming and complex interventions can be avoided, thus "streamlining" the clinical encounter to increase efficiencies of care. This also increases the likelihood of avoiding unnecessary labels surrounding "psychosocial" complexities that many manual therapists feel inadequately prepared to deal with [40].

The items of "patient susceptible to placebo effect" and "the production of a clicking sound (cavitation) at the moment of thrust", although not linked by the experts in this study, could possibly be viewed together. The thrust component without a cavitation can reduce spinal pain [41]. However, there is also evidence that, at least in part, the audible sound produces a placebo effect [42]. This is a psychobiological phenomenon where many mechanisms are at play $[43,44]$. A patient's response to such placebos are well documented and a range of contextual factors have been identified that maximize its effect [45]. This study suggests practitioners who use HVLA SMT believe this has a role to play in patients who obtain immediate relief. Other items on this final list, such as patient expectations previously discussed, also contribute to contextual factors [44]. This raises the question of "Do patients who experience this type of response to HVLA SMT also experience it in other clinical settings or for other health care interventions?" Studies have suggested that the personality traits of optimism, in tandem with low state anxiety, are predictive of a placebo effect [46]. However, research regarding the correlation between personality traits and placebo effects is not consistent, and an individual's expectations appear to play a larger role [47]. A simpler starting point to answer this question, and the role of non-mechanical factors in general in the NSLBP subgroup, may be to conduct qualitative studies seeking the views of patients known to have this type of dramatic response.

While many items were thought to be impacted on by psychosocial factors there was nonetheless a considerable number with a biomechanical focus. Three of the five criteria for the clinical prediction rule for identifying patients with non-radicular low back pain who will 
benefit from SMT [48] were retained and indicated a milder less complicated profile i.e., pain shorter in duration, no radiculopathy or fear-avoidance issues, and reduced or painful (end) ranges of motion. While there is some evidence that patient self-reported changes in motion were predictive of post-SMT immediate improvement [49], the reliability and validity of altered ranges of movement or pain provocation is yet to be demonstrated in clinical trials and is thought to require advanced studies to inform their clinical utility [50-52]. Also, currently the diagnosis of LBP has moved toward clusters of tests [53]. Taken in combination, the findings from this study suggest that experts in HVLA SMT are of the view that this novel cluster of biomechanical factors are worthy of further testing for reliability and validity.

The expert HVLA SMT practitioners demonstrated a wide range of estimates of likely numbers of patients who had an immediate strong response to SMT. Interestingly three practitioners reported never having seen it in their clinical experience. Recent thinking for LBP has reconceptualised it as a recurrent persistent condition, somewhat like asthma, that can better be described in terms of variable trajectories [54]. While it is interesting to speculate on the trajectory and the numbers of patients who are perceived to have an immediately strong response to SMT, ultimately this will be decided by longer-term follow-up studies.

\section{Strengths and limitations of the study}

A recognised Delphi methodology [26] was used to obtain the opinion of experts in the field on a single outcome anecdotally recorded in practice. All experts had a sufficient level of experience (at least 5 years of clinical experience) [25] and were derived from both the chiropractic and manipulative physiotherapy professions who regularly employ HVLA SMT as an intervention. Additionally, the snowball sampling resulted in a high number of Australian participants. Nonetheless, this study involved 19 participants and this sample size raises questions of generalizability.

Also, there is considerable debate about the ability of subgroup analyses to examine treatment-effect modification across NSLBP subgroups defined by patient characteristics [55]. Factors thought to contribute to this uncertainty are poor methodological quality, the absence of a clearly established biological rationale, and heterogeneity of treatment effects [55]. These factors should be borne in mind if attempts are made to further explore the findings of this preliminary investigative study.

Another limitation is the assumption that an immediate response post-SMT is a phenomenon that has objective properties, such as signs and symptoms, that can be used for identification / quantification purposes. The observations of such a response have been derived anecdotally, and the definition of "instantaneous relief" will likely differ among practitioners.

Despite these obvious limitations there is significant evidence that a three-round Delphi such as the one conducted can be successful in establishing its purpose [26].

A successful Delphi effectively identifies differing opinions, acts as an efficient group communication tool to deal with topics of complexity and/or uncertainty, and has the ability of establishing a homogeneous expert opinion or result [25].

\section{Future research}

The 18 factors identified in this study could be formed into an instrument of measurement and then tested for reliability and validity. Such a future study would need to include a variety of patients of differing ages, gender and severity of problem/ condition.

Several of the factors are novel and previously unexplored when seeking to predict patient outcomes to SMT, in particular those related to trust and confidence in the practitioner and susceptibility to placebo. As such they may warrant preliminary investigations before progressing with further subgrouping studies using these 18 items.

\section{Conclusion}

Developing a well-informed decision-making tool regarding the most appropriate manual therapy and treatment strategy for an individual is an admirable goal. Success in this regard would potentially save time, reduce costs, improve treatment outcomes and reduce adverse events from unnecessary treatment.

The 18 factors identified in this study can theoretically be used to create an instrument of measurement that may be used clinically to predict those NSLBP patients who will receive instantaneous relief post-SMT. Future research on these factors and their reliability and validity is recommended.

\section{Supplementary information}

Supplementary information accompanies this paper at https://doi.org/10. 1186/s12998-020-00324-7.

Additional file 1. Round 1 Initial Survey

\section{Abbreviations \\ HVLA: High-velocity low-amplitude; LBP: Low back pain; NSLBP: Non-specific low back pain; SMT: Spinal manipulation therapy}

\section{Acknowledgements}

Antonious Bolas, Matthew Hender, Paul Huerta, Ava Sin Yan Law, Molly McNeill for their contribution in literature searches, and data collection.

\section{Authors' contributions}

BFW was responsible for the study conceptualisation and design. BFW, $\mathrm{CH}$, and $A B$ developed the survey. BFW and $A B$ analysed the data. The initial draft was BFW, $A B, C H, R M, D L, S I$. SI developed the iterative and final drafts. All authors read and approved the final manuscript. 


\section{Funding}

Not applicable.

\section{Availability of data and materials}

Not applicable.

\section{Ethics approval and consent to participate}

Murdoch University Human Research Ethics Committee gave approval for the study 2018/163.

\section{Consent for publication}

Not applicable.

\section{Competing interests}

Bruce Walker (BFW) is Editor-in-Chief of the journal Chiropractic \& Manual Therapies. He did not play any part in the assignment of this manuscript to Associate Editors or peer reviewers and are separated and blinded from the editorial system from submission inception to decision.

\section{Author details}

${ }^{1}$ Psychology, Exercise Science, Counselling and Chiropractic, Murdoch University, Murdoch, Australia. ${ }^{2}$ 5th Year student, Psychology, Exercise Science, Counselling and Chiropractic, Murdoch University, Murdoch, Australia.

\section{Received: 11 March 2020 Accepted: 4 June 2020}

\section{Published online: 02 July 2020}

\section{References}

1. Chiropractic WFC. World Federation of Chiropractic Dictionary. Toronto: 2001.

2. Orrock P. Profile of members of the Australian osteopathic association: part 1-the practitioners. Int J Osteopath Med. 2009;12(1):14-24.

3. WFC Dictionary Definition. Definitions of Chiropractic. https://www.wfc.org/ website/index.php?option=com_content\&view=article\&id=90\&ltemid=110. Accessed 12 Dec 2019

4. Shipton EA. Physical therapy approaches in the treatment of low Back pain. Pain Ther. 2018;7(2):127-37.

5. Gislason HF, Salminen JK, Sandhaugen L, Storbraten AS, Versloot R, Roug I, Newell D. The shape of chiropractic in Europe: a cross sectional survey of chiropractor's beliefs and practice. Chiropr Man Therap. 2019;27:16.

6. Savva C, Giakas G, Efstathiou M. The role of the descending inhibitory pain mechanism in musculoskeletal pain following high-velocity, low amplitude thrust manipulation. A review of the literature. J Back Musculoskelet Rehabil. 2014;27(4):377-82.

7. Flynn T, Fritz J, Whitman J, Wainner R, Magel J, Rendeiro D, Butler B, Garber M, Allison S. A clinical prediction rule for classifying patients with low back pain who demonstrate short-term improvement with spinal manipulation. Spine. 2002;27(24):2835-43.

8. Bronfort $G$, Haas M, Evans R, Leininger B, Triano J. Effectiveness of manual therapies: the UK evidence report. Chiropr Osteopat. 2010;18(1):3.

9. Davis KG, Kotowski SE. Preliminary evidence of the short-term effectiveness of alternative treatments for low back pain. Technol Health Care. 2005;13(6): 453-62.

10. Pickar JG. Neurophysiological effects of spinal manipulation. Spine J. 2002; 2(5):357-71.

11. Cao D-Y, Pickar JG. Effect of spinal manipulation on the development of history-dependent responsiveness of lumbar paraspinal muscle spindles in the cat. J Can Chiropr Assoc. 2014;58(2):149.

12. George SZ, Bishop MD, Bialosky JE, Zeppieri G, Robinson ME. Immediate effects of spinal manipulation on thermal pain sensitivity: an experimental study. BMC Musculoskelet Disord. 2006;7(1):68.

13. Rubinstein SM, Terwee CB, Assendelft WJ, de Boer MR, van Tulder MW. Spinal manipulative therapy for acute low back pain: an update of the cochrane review. Spine. 2013:38(3):E158-77.

14. Coronado RA, Gay CW, Bialosky JE, Carnaby GD, Bishop MD, George SZ. Changes in pain sensitivity following spinal manipulation: a systematic review and meta-analysis. J Electromyogr Kinesiol. 2012;22(5):752-67.

15. Gay CW, Robinson ME, George SZ, Perlstein WM, Bishop MD. Immediate changes after manual therapy in resting-state functional connectivity as measured by functional magnetic resonance imaging in participants with induced low back pain. J Manip Physiol Ther. 2014:37(9):614-27.

16. DALYS GBD, Collaborators H. Global, regional, and national disabilityadjusted life-years (DALYs) for 333 diseases and injuries and healthy life expectancy (HALE) for 195 countries and territories, 1990-2016: a systematic analysis for the global burden of disease study 2016. Lancet. 2017; 390(10100):1260-344.

17. Buchbinder R, van Tulder M, Öberg B, Costa LM, Woolf A, Schoene M, Croft P, Hartvigsen J, Cherkin D, Foster NE. Low back pain: a call for action. Lancet. 2018;391:2384-8.

18. Hoy D, March L, Brooks P, Blyth F, Woolf A, Bain C, Williams G, Smith E, Vos $T$, Barendregt J. The global burden of low back pain: estimates from the global burden of disease 2010 study. Ann Rheum Dis. 2014;73(6):968-74

19. Innes SI, Leboeuf-Yde C, Walker BF. Chiropractic student choices in relation to indications, non-indications and contra-indications of continued care. Chiropr Man Therap. 2018;26:3

20. Goncalves G, Demortier M, Leboeuf-Yde C, Wedderkopp N. Chiropractic conservatism and the ability to determine contra-indications, nonindications, and indications to chiropractic care: a cross-sectional survey of chiropractic students. Chiropr Man Therap. 2019;27(1):3.

21. Childs J, Fritz J, Flynn T. A clinical prediction rule to identify patients with low back pain most likely to benefit from spinal manipulation: a validation study. Altern Med Rev. 2005;10(1):66-7.

22. Axen I, Rosenbaum A, Robech R, Larsen K, Leboeuf-Yde C. The Nordic back pain subpopulation program: can patient reactions to the first chiropractic treatment predict early favorable treatment outcome in nonpersistent low back pain? J Manip Physiol Ther. 2005;28(3):153-8.

23. Axen I, Rosenbaum A, Robech R, Wren T, Leboeuf-Yde C. Can patient reactions to the first chiropractic treatment predict early favorable treatment outcome in persistent low back pain? J Manip Physiol Ther. 2002; 25(7):450-4

24. Newell D, Field J, Visnes N. Prognostic accuracy of clinicians for back, neck and shoulder patients in routine practice. Chiropr Manual Ther. 2013;21(1):42.

25. Jünger S, Payne SA, Brine J, Radbruch L, Brearley SG. Guidance on conducting and REporting DElphi studies (CREDES) in palliative care: recommendations based on a methodological systematic review. Palliat Med. 2017;31(8):684-706.

26. Hasson F, Keeney S, McKenna H. Research guidelines for the Delphi survey technique. J Adv Nurs. 2000;32(4):1008-15.

27. Linstone HA, Turoff M. The delphi method: Addison-Wesley Reading, MA; 1975

28. Powell C. The Delphi technique: myths and realities. J Adv Nurs. 2003;41(4): 376-82.

29. Survey Monkey Inc. San Mateo, California. https://www.Surveymonkey.com.

30. Eklund A, Jensen I, Lohela-Karlsson M, Hagberg J, Leboeuf-Yde C, Kongsted A, Bodin L, Axen I. The Nordic maintenance care program: effectiveness of chiropractic maintenance care versus symptom-guided treatment for recurrent and persistent low back pain-a pragmatic randomized controlled trial. PLoS One. 2018;13(9):e0203029.

31. Bishop MD, Mintken PE, Bialosky JE, Cleland JA. Patient expectations of benefit from interventions for neck pain and resulting influence on outcomes. J Orthop Sports Phys Ther. 2013;43(7):457-65.

32. Herman PM, Whitley MD, Ryan GW, Hurwitz EL, Coulter ID. The impact of patient preferences and costs on the appropriateness of spinal manipulation and mobilization for chronic low back pain and chronic neck pain. BMC Musculoskelet Disord. 2019;20(1):519.

33. Martin DJ, Garske JP, Davis MK. Relation of the therapeutic alliance with outcome and other variables: a meta-analytic review. J Consult Clin Psychol. 2000;68(3):438-50.

34. Kushner SC, Quilty LC, Uliaszek AA, McBride C, Bagby RM. Therapeutic alliance mediates the association between personality and treatment outcome in patients with major depressive disorder. J Affect Disord. 2016; 201:137-44

35. Lambers NM, Bolton JE. Perceptions of the quality of the therapeutic alliance in chiropractic care in the Netherlands: a cross-sectional survey. Chiropr Man Therap. 2016;24:18.

36. Ferreira PH, Ferreira ML, Maher CG, Refshauge KM, Latimer J, Adams RD. The therapeutic alliance between clinicians and patients predicts outcome in chronic low back pain. Phys Ther. 2013;93(4):470-8.

37. Verkerk K, Luijsterburg PA, Heymans MW, Ronchetti I, Pool-Goudzwaard AL, Miedema HS, Koes BW. Prognosis and course of pain in patients with 
chronic non-specific low back pain: a 1-year follow-up cohort study. Eur J Pain. 2015;19(8):1101-10.

38. Verkerk K, Luijsterburg PA, Pool-Goudzwaard A, Heymans MW, Ronchetti I, Miedema HS, Koes BW. Prognosis and course of work-participation in patients with chronic non-specific low back pain: a 12-month follow-up cohort study. J Rehabil Med. 2015;47(9):854-9.

39. Alhowimel A, AlOtaibi M, Radford K, Coulson N. Psychosocial factors associated with change in pain and disability outcomes in chronic low back pain patients treated by physiotherapist: a systematic review. SAGE Open Med. 2018;6:2050312118757387.

40. Synnott A, O'Keeffe M, Bunzli S, Dankaerts W, O'Sullivan P, O'Sullivan K. Physiotherapists may stigmatise or feel unprepared to treat people with low back pain and psychosocial factors that influence recovery: a systematic review. J Phys. 2015;61(2):68-76.

41. Bialosky JE, Bishop MD, Robinson ME, Zeppieri G Jr, George SZ. Spinal manipulative therapy has an immediate effect on thermal pain sensitivity in people with low back pain: a randomized controlled trial. Phys Ther. 2009: 89(12):1292-303

42. Bakker M, Miller J. Does an audible release improve the outcome of a chiropractic adjustment? J Can Chiropr Assoc. 2004;48(3):237.

43. Benedetti F, Mayberg HS, Wager TD, Stohler CS, Zubieta J-K. Neurobiological mechanisms of the placebo effect. J Neurosci. 2005;25(45):10390-402.

44. Newell D, Lothe LR, Raven TJL. Contextually aided recovery (CARe): a scientific theory for innate healing. Chiropr Man Therap. 2017:25:6.

45. Rossettini G, Carlino E, Testa M. Clinical relevance of contextual factors as triggers of placebo and nocebo effects in musculoskeletal pain. BMC Musculoskelet Disord. 2018;19(1):27.

46. Morton DL, Watson A, El-Deredy W, Jones AK. Reproducibility of placebo analgesia: effect of dispositional optimism. Pain. 2009;146(1-2):194-8.

47. Whalley B, Hyland ME, Kirsch I. Consistency of the placebo effect. J Psychosom Res. 2008;64(5):537-41.

48. Childs JD, Fritz JM, Flynn TW, Irrgang JJ, Johnson KK, Majkowski GR, Delitto A. A clinical prediction rule to identify patients with low back pain most likely to benefit from spinal manipulation: a validation study. Ann Intern Med. 2004;141(12):920-8

49. Thiel HW, Bolton JE. Predictors for immediate and global responses to chiropractic manipulation of the cervical spine. J Manip Physiol Ther. 2008; 31(3):172-83.

50. Laird RA, Kent P, Keating JL. How consistent are lordosis, range of movement and lumbo-pelvic rhythm in people with and without back pain? BMC Musculoskelet Disord. 2016;17(1):403.

51. Lemeunier N, Jeoun EB, Suri M, Tuff T, Shearer H, Mior S, Wong JJ, da SilvaOolup S, Torres P, D'Silva C, et al. Reliability and validity of clinical tests to assess posture, pain location, and cervical spine mobility in adults with neck pain and its associated disorders: part 4. A systematic review from the cervical assessment and diagnosis research evaluation (CADRE) collaboration. Musculoskelet Sci Pract. 2018;38:128-47.

52. McIntosh G, Steenstra I, Hogg-Johnson S, Carter T, Hall H. Lack of prognostic model validation in low Back pain prediction studies: a systematic review. Clin J Pain. 2018:34(8):748-54.

53. Petersen $T$, Laslett M, Juhl C. Clinical classification in low back pain: bestevidence diagnostic rules based on systematic reviews. BMC Musculoskelet Disord. 2017;18(1):188

54. Kongsted A, Kent P, Axen I, Downie AS, Dunn KM. What have we learned from ten years of trajectory research in low back pain? BMC Musculoskelet Disord. 2016;17:220.

55. Saragiotto BT, Maher CG, Hancock MJ, Koes BW. Subgrouping patients with nonspecific low Back pain: Hope or hype? J Orthop Sports Phys Ther. 2017; 47(2):44-8.

\section{Publisher's Note}

Springer Nature remains neutral with regard to jurisdictional claims in published maps and institutional affiliations.

Ready to submit your research? Choose BMC and benefit from:

- fast, convenient online submission

- thorough peer review by experienced researchers in your field

- rapid publication on acceptance

- support for research data, including large and complex data types

- gold Open Access which fosters wider collaboration and increased citations

- maximum visibility for your research: over $100 \mathrm{M}$ website views per year

At $\mathrm{BMC}$, research is always in progress.

Learn more biomedcentral.com/submissions 